\title{
Notes on the vocalizations of Blissett's Wattle-eye (Dyaphorophyia blissetti)
}

Peter Boesman

In the following we briefly analyze and compare voice of the three races of Blissett's Wattleeye (Dyaphorophyia blissetti). We also try to quantify the extent of any vocal differences using the criteria proposed by Tobias et al. (2010), as a support for taxonomic review.

We have made use of sound recordings available on-line from Xeno Canto (XC) and Macaulay Library (ML).

From the available recordings, it would seem that voice of the three races is quite different:

race blissetti $(n=16)$

Voice is typically a series of about $4-7$ short notes at same pitch $(3500-3800 \mathrm{~Hz})$. Often also longer series.

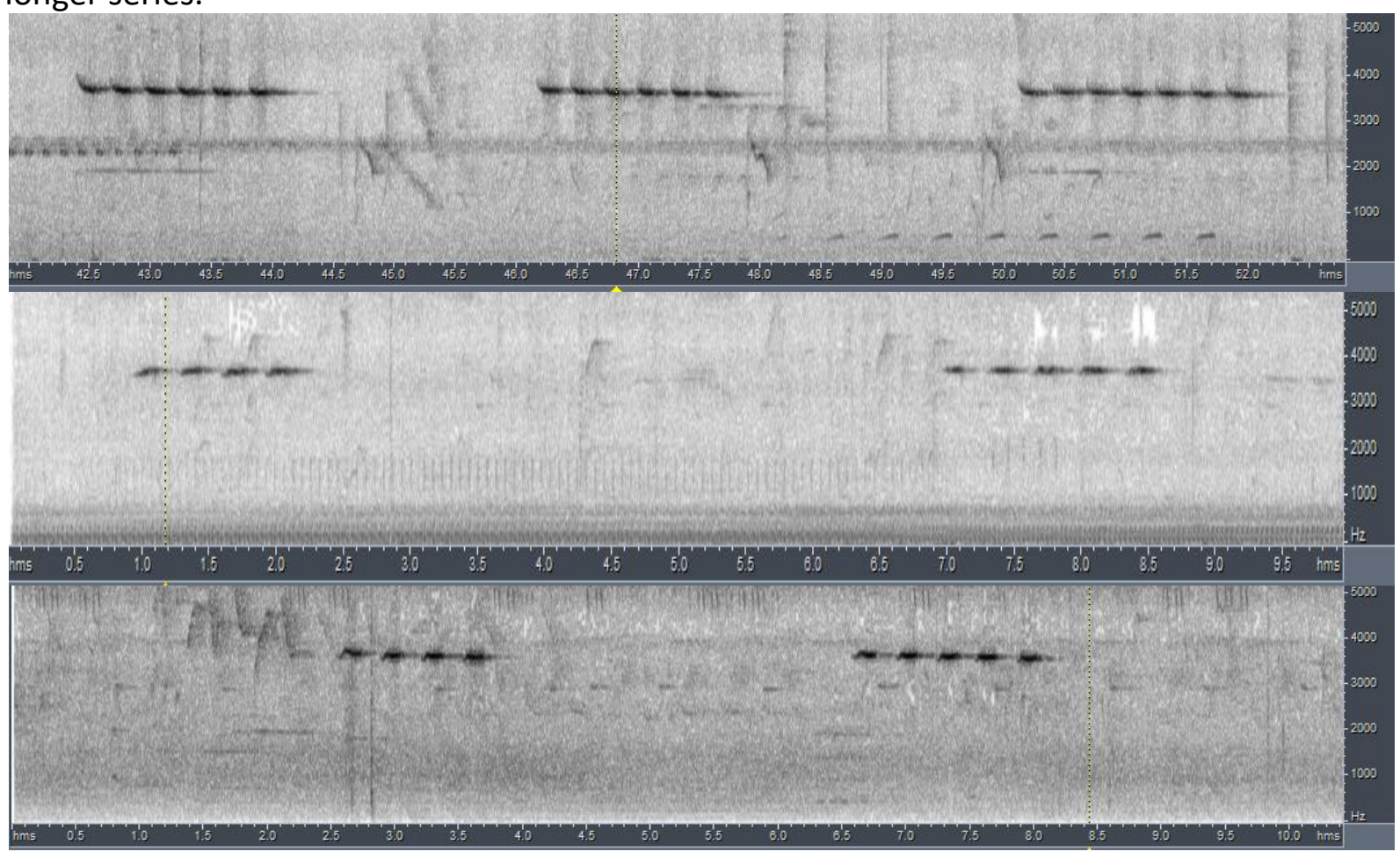

race chalybea $(n=2)$

Voice is a descending series of 4-6 short whistles (first note above $5000 \mathrm{~Hz}$ ).

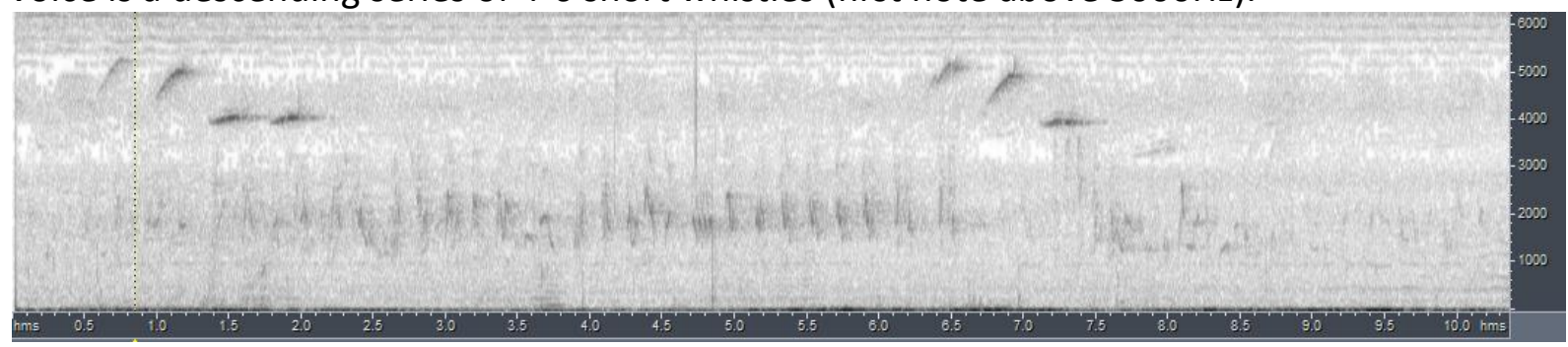



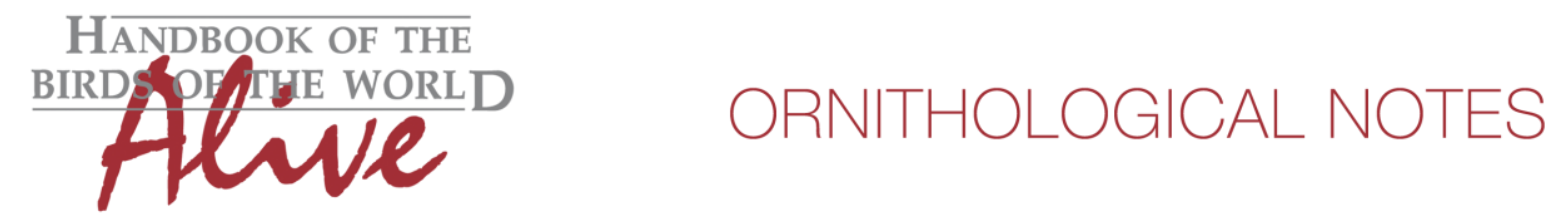

race jamesoni $(n=14)$

Voice is a single or double note repeated. Notes lie within a narrow frequency range (3800$4500 \mathrm{~Hz})$.

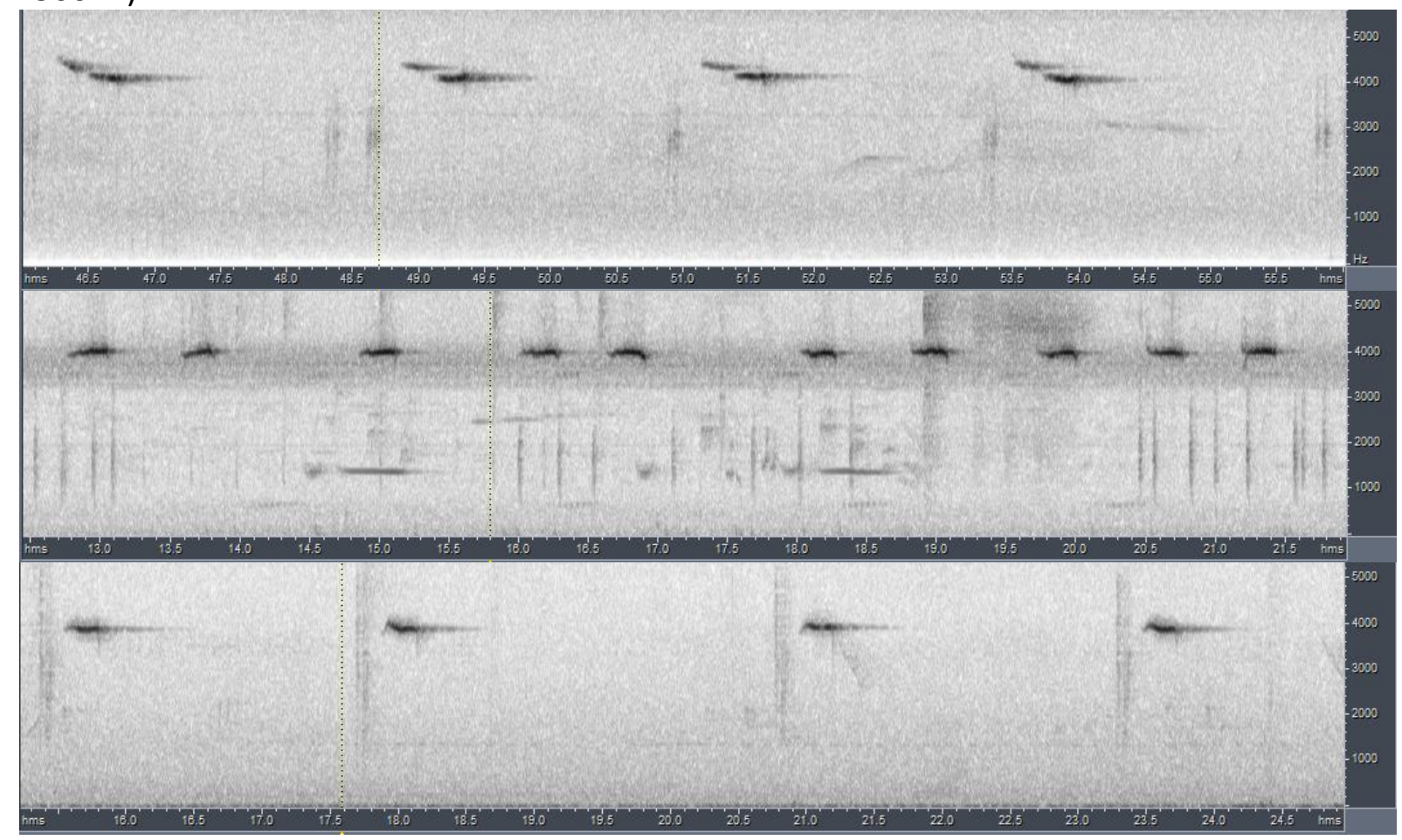

From the above, vocal differences are quite clear:

jamesoni has single or double notes repeated with more or less constant pauses (score 3-4). Notes are slightly longer in duration and higher-pitched than blissetti (score 1-2). Frequency range is much smaller than chalybea (score 3 ).

When applying Tobias criteria, this would lead to a total vocal score of about 4 vs. blissetti and about 6 vs. chalybea.

chalybea has a larger frequency range than blissetti (score 3) reaching higher frequencies (2), and a phrase consisting of different notes (score 1), which are descending in pitch (score 2).

Total vocal score 4-5.

The number of available recordings is small for race chalybea, but voice also confirmed by description in HBW "4-6 descending sweet notes" (Louette 2015).

This note was finalized on 17th November 2015, using sound recordings available on-line at that moment. We would like to thank in particular the sound recordists who placed their recordings for this species on XC and ML: Louis Boon, Sander Bot, James Bradley, Scott Connop, Jacob Cooper, Phil Gregory, Mark Harper, Peter Kaestner, Frank Lambert, Linda Macaulay, David Moyer, Mike Nelson, Bram Piot, Martin St-Michel, Crammy Wanyama and Dale Zimmerman. 


\section{References}

Louette, M. (2015). Blissett's Wattle-eye (Dyaphorophyia blissetti). In: del Hoyo, J., Elliott, A., Sargatal, J., Christie, D.A. \& de Juana, E. (eds.). Handbook of the Birds of the World Alive. Lynx Edicions, Barcelona. (retrieved from http://www.hbw.com/node/59133 on 17 November 2015).

Tobias, J.A., Seddon, N., Spottiswoode, C.N., Pilgrim, J.D., Fishpool, L.D.C. \& Collar, N.J. (2010). Quantitative criteria for species delimitation. Ibis 152(4): 724-746.

\section{Recommended citation}

Boesman, P. (2016). Notes on the vocalizations of Blissett's Wattle-eye (Dyaphorophyia blissetti). HBW Alive Ornithological Note 185. In: Handbook of the Birds of the World Alive. Lynx Edicions, Barcelona. (retrieved from http://www.hbw.com/node/932124 on 25 August 2016). 